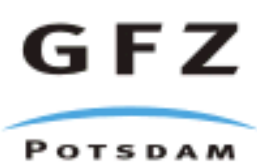

Originally published as:

Bender, M., Dick, G., Wickert, J., Schmidt, T., Song, S., Gendt, G., Ge, M., Rothacher, M. (2008): Validation of GPS slant delays using water vapour radiometers and weather models. Meteorologische Zeitschrift, 17, 6, 807-812

DOI: $10.1127 / 0941-2948 / 2008 / 0341$ 


\title{
Validation of GPS slant delays using water vapour radiometers and weather models
}

\author{
Michael Bender $^{1 *}$, GAlina Dick ${ }^{1}$, Jens WiCKert ${ }^{1}$, TORSTEn SCHMidT ${ }^{1}$, Shuli Song $^{2}$, \\ GERD GENDT $^{1}$, MAORONG GE $^{1}$ and MARKUS ROTHACHER ${ }^{1}$
}

${ }^{1}$ Helmholtz-Zentrum Potsdam, Deutsches GeoForschungsZentrum, Potsdam, Germany

${ }^{2}$ Shanghai Astronomical Observatory, CAS, Shanghai, China

(Manuscript received February 26, 2008; in revised form October 9, 2008; accepted October 9 1, 2008)

\begin{abstract}
Slant delay data obtained from global positioning system (GPS) observations carry valuable meteorological information. The spatial distribution of the water vapour can be reconstructed from such slant delays. To estimate the quality of the GPS slant delays two validation studies were carried out. One study was based on the observations of a water vapour radiometer, a second on the analysis fields of a numerical weather model which were used to compute the corresponding GPS delays. Both studies yielded a high correlation between the available slant delays at higher elevation angles but showed deficiencies at low elevations. The mean bias between the GPS zenith delays and the radiometer data is $1.18 \mathrm{~mm}$ with a RMS of $6.0 \mathrm{~mm}$. The corresponding bias and RMS of the GPS vs. model comparison are $3.3 \mathrm{~mm}$ and $2.9 \mathrm{~mm}$.
\end{abstract}

\begin{abstract}
Zusammenfassung
Die Laufzeitverzögerung der GPS-Signale in der Atmosphäre kann wertvolle meteorologische Informationen liefern. Insbesondere ist es möglich, die räumliche Wasserdampfverteilung in der Troposphäre aus den Laufzeitdaten zu rekonstruieren. Hierzu muß jedoch zunächst die Qualität der GPS-Daten durch ValidierungsStudien ermittelt werden. Hier werden zwei Studien beschrieben: In der ersten werden die GPS-Daten mit denen eines Wasserdampf-Radiometers verglichen, in der zweiten werden die Analysen eines numerischen Wettermodells genutzt, um die GPS-Signal-Laufzeiten zu berechnen und mit den Beobachtungen zu vergleichen. In beiden Fällen ergibt sich eine gute Übereinstimmung für größere Elevationen, bei niedrigen Elevationen treten jedoch größere Abweichungen auf. Insgesamt ergibt sich eine mittlere Abweichung von $1,18 \mathrm{~mm}$ und ein RMS von 6,0 $\mathrm{mm}$ zwischen den Zenitdelays aus Radiometerbeobachtungen und der GPSAnalyse und eine Abweichung von 3,3 mm mit einem RMS von 2,9 mm zu den Modelldaten.
\end{abstract}

\section{Introduction}

A severe problem of quantitative precipitation forecasts is the lack of spatially resolved humidity information, especially on the vertical profile of the water vapour distribution. The new high-resolution numerical weather models required to obtain reliable precipitation forecasts need a realistic initialisation of the synoptic fields. Such observations with a sufficiently high spatial resolution can only be provided by remote sensing techniques. The upcoming ground-based GPS atmosphere sounding techniques are about to provide humidity fields with a high temporal and spatial resolution under all weather conditions.

GPS remote sensing techniques make use of the existing infrastructure of GPS satellites and geodetic ground networks. Only a sophisticated processing of the GPS data is required to extract the humidity information. Such analysis techniques are currently developed all over the world and need to be validated for a wide

\footnotetext{
* Corresponding author: M. Bender, Helmholtz-Zentrum Potsdam, Deutsches GeoForschungsZentrum, Telegrafenberg, 14473 Potsdam, Germany, e-mail: bender@gfz-potsdam.de
}

range of weather conditions. Unfortunately, there are currently only few reliable observations available which could be used as a reference and efforts have to be made to receive humidity data with a quality comparable to the GPS observations. Water vapour radiometers (WVR) use an established method and provide slant wet delays which can directly be compared to the slant wet delays (SWD) obtained from the GPS data processing. The only problem is to synchronise the WVR operation with the GPS receiver which tracks usually several GPS satellites in different directions simultaneously.

Another way for validating GPS observations is to use the analysis fields of numerical weather models. A large number of meteorological observations is continuously assimilated to the operational forecast models and their representation of the synoptic parameters is the best approximation available of the real state of the atmosphere. These analysis fields can therefore be used to estimate the GPS slant delays due to the neutral atmosphere at least in situations where the model state was close to the real weather condition. As the validation not have to be carried out in real-time some suitable weather situations can be selected. This work describes a first validation study carried out with the recently analysed 
slant delay data of the GFZ. The STDs were validated using a Radiometrics WVR-1100 operated at Wettzell and analysis fields of the COSMO-EU model.

\section{GPS data analysis at the GFZ Potsdam}

The GPS network analysed in near real-time at GFZ consists presently of about 220 sites in Germany and neighbouring countries. The data analysis is performed on an hourly basis with a delay of about 30 minutes using the GFZ EPOS software which is based on a least squares adjustment of undifferenced phase measurements. For meteorological applications the GPS data are processed in a sliding window mode with a window length of 12 hours and a forward step of one hour. The technique of parallel analysis of station clusters with the "Precise Point Positioning" (PPP) strategy (ZUMBERGE et al., 1997) is implemented to obtain the results of dense networks within 10 minutes computing time (DICK et al., 2001; GENDT et al., 2004). The high quality orbits and clocks required by the PPP analysis are determined by further refining the IGS routine products. All GPS data are taken with a sampling period of $2.5 \mathrm{~min}$ and an elevation cut-off angle of $7^{\circ}$. This work is based on the operational version of EPOS used during COPS in summer 2007. As these data were used by several groups during COPS (CREWELL et al., 2008) it is important to validate them carefully. A new considerably advanced version of EPOS which makes, e. g., use of the ViennaMapping Function (VMF) (BoEHM et al., 2006) will become operational in near the future.

The EPOS software is also used by the IGS Analysis Centre (GENDT et al., 1999) located at the GFZ to obtain high precision solutions for geodetic applications. The GFZ website (www.gfz-potsdam.de) gives access to the real-time quality monitoring of all available GPS stations processed at the GFZ and the E-GVAP website (egvap.dmi.dk) shows the performance of the GFZ GPS analysis in relation to other processing centres and the HIRLAM weather model.

Basically two products are provided for meteorological applications, i. e. the zenith total delay (ZTD) and the slant total delay (STD). The ZTD is a combined quantity based on all data taken during one hour by each station. The available GPS observations are analysed in order to find an optimal parameter estimation for the zenith delay in 15 min steps. The ZHD is estimated using the Saastamoinen model and an a priori model which describes the latitude and longitude dependent variation of the meteorological parameters. The wet Niell mapping function (NIELL, 1996) is used to compute the partial derivative. Closely related to the ZTD is the integrated water vapour (IWV) which can be obtained from the ZTD and some meteorological surface observations (BEVIS et al., 1994; DICK et al., 2001). Another result of the GPS analysis are the STDs, i. e. the signal delays along each single signal path. The major part of the STD is obtained using the previously described ZTDs and the wet Neill mapping function which yields the projection of the ZTD on the transmitter receiver path. The residuals of the least squares adjustment are added to this part to provide information of the anisotropic atmospheric impact on the slant delay. The least squares solution considers all individual slants of a given station and makes use of the full temporal resolution of $2.5 \mathrm{~min}$.

During 2006 the GFZ started to analyse STDs operationally for about 130 German GPS stations leading to about 800000 slant data per day. Each slant path represents a different view through the atmosphere and the corresponding delay is an integral representation of the atmospheric state in this direction. These data carry valuable meteorological information, especially on the water vapour distribution.

\section{Validation using a Water Vapour Radiometer}

Information about the distribution of liquid water and water vapour can be obtained from WVR observations. WVRs analyse the microwave spectrum emitted by the atmospheric water molecules and can provide SWD data which are independent from the corresponding GPS values. The observations of a Radiometrics WVR-1100 radiometer operated by the BKG at Wettzell were used to validate the results from the GFZ GPS analyses. The WVR-1100 is a dual-frequency radiometer operating at $23.8 \mathrm{GHz}$ for water vapour observations and at $31.4 \mathrm{GHz}$ for liquid water observations. The path delays due to liquid water and the water vapour (SWD) are obtained from the brightness temperatures measured at these two frequencies using the Radiometrics retrieval algorithm (SOLHEIM et al., 1998). The retrieval is based on a bilinear regression using simulated brightness temperatures from radiosonde calibrations. After calibration a RMS of 3-4 mm was observed with a temporal resolution of 5 min. A time series of 25 days in October 2006 was available from the routine observations, i. e. the WVR was cycling through several discrete azimuth and elevation angles which were not at all correlated to the positions of GPS satellites. It was therefore necessary to select a subset of GPS observations where the WVR was nearly pointing in the direction of a certain GPS satellite. All GPS slant data with an azimuth difference below $15^{\circ}$, an elevation difference below $0.05^{\circ}$ and a temporal distance below 15 minutes were chosen for the validation.

The WVR provides SWD data while the operational GPS analysis results in slant total delays (STDs) and it was necessary to convert the data for the comparison. The Saastamoinen hydrostatic zenith delay (ZHD) estimated using meteorological observations at the station Wettzell was mapped to the individual slant paths using the wet Niell mapping function. The hydrostatic part (SHD) was added to the WVR SWD data in order to 


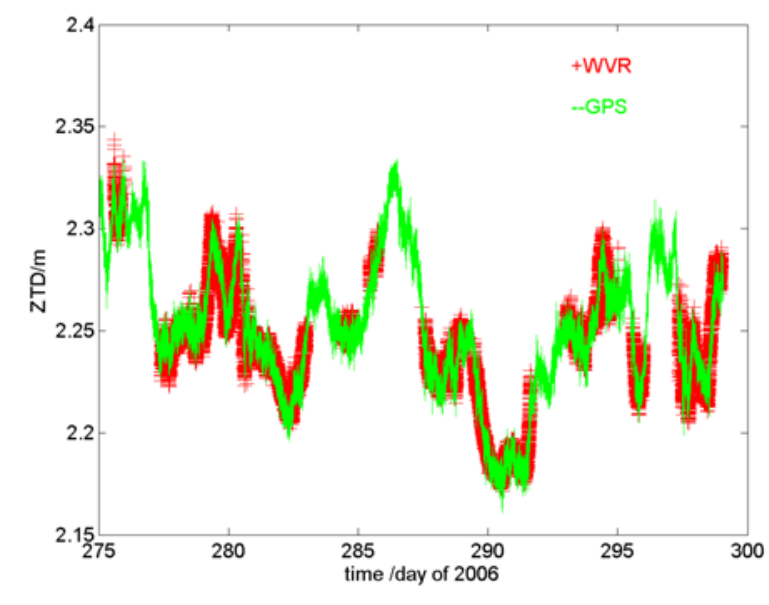

Figure 1: Comparison of GPS slant total delays with the delays from WVR measurements at the station Wettzell. In both cases the data were mapped to the zenith direction. The period covers 25 days in October 2006.

Table 1: Difference between the slant delays obtained with GPS and a WVR for 20 days in 2007 : Daily bias and RMS. The RMS could be reduced by removing the residual stacking maps from the observations: $\mathrm{RMS}_{1}$ - raw GPS data, $\mathrm{RMS}_{2}$ - after application of the stacking maps.

\begin{tabular}{crccc}
\hline Elevation & $N$ & Bias [mm] & $\mathrm{RMS}_{1}[\mathrm{~mm}]$ & $\mathrm{RMS}_{2}[\mathrm{~mm}]$ \\
\hline $5^{\circ}-15^{\circ}$ & 92 & 1.40 & 9.24 & 8.90 \\
$20^{\circ}-30^{\circ}$ & 64 & 1.30 & 2.70 & 2.65 \\
$40^{\circ}-50^{\circ}$ & 39 & 0.61 & 1.32 & 1.19 \\
$60^{\circ}-75^{\circ}$ & 26 & 0.93 & 1.77 & 1.75 \\
\hline $5^{\circ}-75^{\circ}$ & 221 & 1.18 & 6.19 & 5.97 \\
\hline
\end{tabular}

compare the STD values. The corresponding ZTDs, i. e. the STDs mapped back into zenith direction, are shown in Figure 1. The results agree very well but there is a small bias up to $1.4 \mathrm{~mm}$ which depends on the elevation (see Table 1).

In order to improve the GPS STDs at low elevations the stacking technique (SHOJI et al., 2004) was applied to the GPS residuals. This technique is widely used to eliminate antenna phase centre variations (PCV) and multipath effects. These effects lead to systematic deviations in certain directions and have to be corrected separately for each station and each antenna type. The basic tool is the stacking map, i. e. the mean residual from the GPS processing in a certain elevation-azimuth interval. Corrections of up to $20 \mathrm{~mm}$ in the slant delay are applied to the GPS data of a certain station.

In this study a stacking map with $1^{\circ}$ intervals of the elevation and azimuth angles was estimated. GPS data from varying periods between 1 and 30 days were used to constitute the stacking maps leading to an optimal interval of 7 days. The correspondence between WVR and GPS could slightly be improved this way. The RMS was reduced, especially at low elevation angles (Table 1), but the bias could not be changed considerably. It must be pointed out that the differences are already very small ( $<1 \mathrm{~mm}$ for $\varepsilon>30^{\circ}$ ) and that WVRs also have their difficulties at low elevations (POTTIAUX and WARNANT, 2002). The bias will therefore also have contributions from the WVR.

\section{Validation using the COSMO-EU Model of the DWD}

For this study the analyses from the operational shortrange numerical weather model COSMO-EU of the German Weather Service (DWD) were used. The COSMOEU model is provided by the Consortium for Small-scale Modeling (COSMO - http://cosmo-model.cscs.ch) and is developed jointly by several European weather services. It is a non-hydrostatic limited area model covering most parts of Europe with a horizontal resolution of $7 \mathrm{~km}$ and 40 hybrid vertical levels up to $30 \mathrm{hPa}(22$ $\mathrm{km})$. The hybrid vertical levels follow the Earth surface at the lowest levels and pressure levels at higher altitudes. The vertical resolution is maximal in the boundary layer and decreases with increasing hight (SCHULZ and SCHÄTTLER, 2005). The analysis fields are obtained using the nudging assimilation method which is based on relaxing the model's prognostic variables towards the available observations (SCHRAFF and HESS, 2003). At present the COSMO-EU nudging process considers synoptic surface observations, upper level measurements from radiosondes (wind, temperature and humidity) and aircraft observations (wind, temperature). GPS data are not yet assimilated to the COSMO-EU model. Main run cycles consisting of an analysis and a forecast run are started 8 times per day. In addition to these main assimilation runs an assimilation analysis is started every hour using an extended cut-off period for the observations in order to assimilate as many observations as possible. The assimilation analyses were used for this work as they are available in hourly intervals and have an improved quality compared to the 4 hour main run analyses.

These analyses provide all information necessary to compute 3D fields of the atmospheric refractivity $N$ and can therefore be used to generate GPS delays. These data were used to estimate the slant total delays and zenith delays for all GPS slant paths observed during the period 1-3 March 2006. Comparing the simulated delays with the observations gives a first impression of the GPS data quality.

\subsection{Slant delay simulation}

The slant total delay (STD) is the delay of the GPS signal caused by Earth's neutral atmosphere as given by BEVIS et al. (1992)

$$
S T D=\Delta L=10^{-6} \int_{s} N(s) d s,
$$


where $N=(n-1) \cdot 10^{6}$ is the refractivity of the atmosphere and $S$ is the ray path from the GPS satellite to the receiver. The STD is defined as the difference $\Delta L$ between the optical length and the geometric distance. To compute STD values a spatially resolved field of the refractivity $N$ is required. The fields of temperature $T$, pressure $p$ and specific humidity $q$ are part of the COSMO-EU analyses and can be used to compute the atmospheric refractivity, e. g. using the empirical Smith \& Weintraub model (SMITH and WEINTRAUB, 1953)

$$
N=k_{1} \cdot \frac{p_{d}}{T}+k_{2} \cdot \frac{e}{T}+k_{3} \cdot \frac{e}{T^{2}},
$$

where $T$ is given in Kelvin, $p_{d}$ is the partial pressure of dry air in $\mathrm{hPa}$ and $e$ is the partial pressure of water vapour in $\mathrm{hPa}$. The constants $k_{1}=77.60 \frac{K}{h P a}, k_{2}=$ $70.40 \frac{K}{h P a}$ and $k_{3}=3.739 \cdot 10^{5} \frac{K^{2}}{h P a}$ as given by BEVIS et al. (1994) were used in this study.

The COSMO-EU fields are defined on a discrete grid with hybrid vertical levels which follow the Earth surface and have a high resolution near the boundary layer which decreases for increasing altitudes. Such discrete grids cannot directly be used to compute the line integral in Equation 4.1 as assumptions about the gradient between neighbouring grid points must be made. In this study an inverse distance weighted interpolation was used to compute a large number of $N$-values along each slant path. The point density along the path was scaled with the air pressure to weight the lower parts of the atmosphere accordingly and the total number of points was scaled with the path length inside the COSMO-EU region. In total approx. 100-500 points on the ray path were interpolated depending on the elevation.

The slant path $S$ as used in Equation 4.1 is in general not a straight line. The ray bending due to the increasing refractivity at lower altitudes leads to slant delays which are smaller than the delays computed using straight lines (SOKOLOVSKIY et al., 2001). This effect becomes important at lower elevations where the ray bending leads to differences of $\sim 3 \mathrm{~cm}$ at $\varepsilon=10^{\circ}$ and $\sim 17 \mathrm{~cm}$ at $\varepsilon=5^{\circ}$. The corresponding STDs are $\sim 13 \mathrm{~m}$ and $\sim 23.5 \mathrm{~m}$. However, a straight line was assumed in this first study. The connecting line between the GPS satellite and the receiver was taken from the observed data and the delay was computed numerically using Equation 4.1 .

In contrast to the wet refractivity the hydrostatic refractivity cannot be neglected above the tropopause region and not even above the COSMO-EU region $(>22$ $\mathrm{km})$. The NRLMSISE-00 empirical atmospheric model (see PICONE et al. (2002) and references therein) was used to describe the refractivity above the upper level of the COSMO-EU region. This model gives a refractivity of $N=21.12$ at $20 \mathrm{~km}$ altitude which decreases to $N=1.2 \cdot 10^{-4}$ at $100 \mathrm{~km}$. The atmospheric delay above $100 \mathrm{~km}$ was neglected as it would lead to path delays below one micrometer. In total the NRLMSISE-00 model

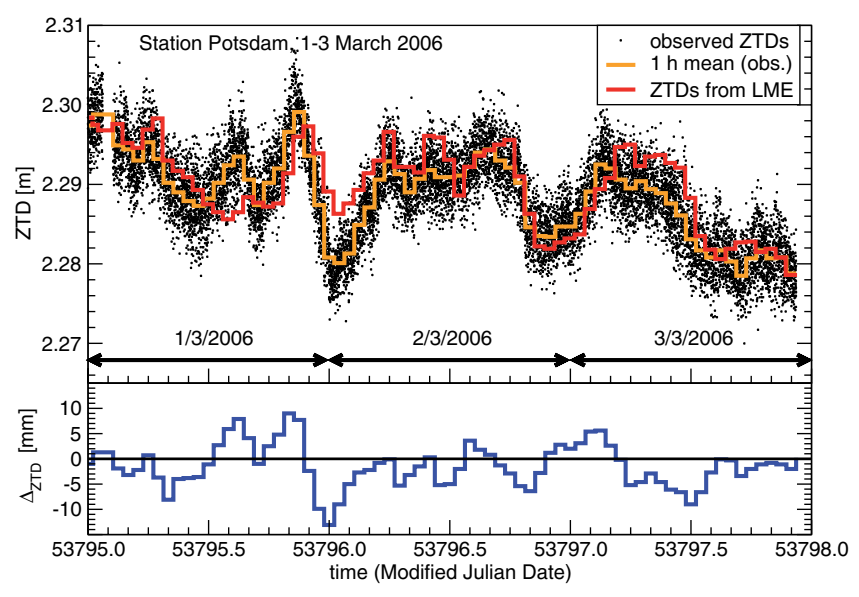

Figure 2: Time series of all observed STDs mapped back to zenith direction $(\bullet)$, their $1 \mathrm{~h}$ mean (orange) and the ZTDs simulated using the COMO-EU analyses (red). The difference between the mean value of the observations and the ZTD simulation is shown below. The GPS station tracks all visible satellites resulting in 6-12 observations at the same time.

provides an additional zenith total delay of approx. $7 \mathrm{~cm}$ for altitudes above $22 \mathrm{~km}$.

For this validation study all observed slant delays from 1 to 3 March 2006 were simulated using the corresponding COSMO-EU analyses.

\subsection{Model - observation inter comparison}

In March 2006 the data of $\sim 130$ German GPS stations were processed operationally (GENDT et al., 2001, 1999). The STD data from 3 days (1/3-3/3/2006) were validated using the COSMO-EU analyses available from the DWD. Among the observed data are the STDs for each station and each GPS satellite and the corresponding ZTDs obtained from the STDs by applying the Niell mapping function (NIELL, 1996). As the STD depends on the elevation and reaches from $\sim 2.3 \mathrm{~m}$ for $\varepsilon \approx 90^{\circ}$ to more than $25 \mathrm{~m}$ for $\varepsilon \leq 7^{\circ}$ it is only for the purpose of comparison mapped back to zenith direction. Confusingly enough, these STDs mapped back to the zenith are usually also referred to as ZTDs and should not be confounded with the ZTDs described at the beginning of section 4.

For each observed STD a corresponding delay was simulated using the model analyses. As analyses were available only in $1 \mathrm{~h}$ intervals all data within that hour were simulated with the same analysis. For comparison these simulated STDs were also mapped to the zenith direction using the same Niell mapping function as in case of the observations. The $1 \mathrm{~h}$ ZTD mean values of the observations and the simulated data as well are provided for comparison.

The time series of the ZTD give a first impression of the situation, e. g. at the station Potsdam in Figure 2. The ZTD is a function of temperature and pressure $(\sim 90 \%)$ 
and humidity (up to $10 \%$ ). Its temporal variability is dominated by fast changes of the humidity field. This variability is represented very well by the GPS observations. The variance of the observations (black dots in Figure 2) has several reasons. The main contribution is from to the slant paths which propagate through different parts of the atmosphere. The distance to the tropopause is $\sim 12 \mathrm{~km}$ in zenith direction but can be up to $100 \mathrm{~km}$ for low elevation slant paths with $\varepsilon \geq 5^{\circ}$. Observations from different regions of the atmosphere are in these cases mapped to the zenith and one cannot expect to obtain the same value. Another problem is the experimental error caused, e. g., by multipath effects or antenna phase centre variations. For comparison with the COSMO-EU model only the mean value is used. For the GPS station Potsdam the difference is most of the time below $10 \mathrm{~mm} Z \mathrm{ZTD}$, the mean deviation between the GPS ZTDs and the model ZTDs is $3.3 \mathrm{~mm}$ with an RMS of $2.9 \mathrm{~mm}$. As can be seen in Figure 2 there are situations where the model propagates differently from the atmosphere leading to rather large deviations. The deviations become very small if the model represents the atmosphere very well.

The correlation between model and observations is not equally well for all stations. Some stations show an offset of more than $20 \mathrm{~mm}$. This might be due to technical problems, but most of these stations are close to the sea or at high altitudes and it can be assumed that the model is less reliable in these regions.

More important than the ZTD is the STD as this quantity would be required to obtain spatially resolved information. The STD depends strongly on the elevation $\varepsilon$ and the length of the ray path in the lower atmosphere. Typical values of the STD are $2.3 \mathrm{~m}$ in zenith direction and $\sim 20 \mathrm{~m}$ at an elevation of $7^{\circ}$. To compare STDs from different elevations the relative deviation between observation and model was used:

$$
\Delta_{\mathrm{STD}}=\frac{S T D_{\mathrm{obs}}-S T D_{\mathrm{mod}}}{S T D_{\mathrm{obs}}} .
$$

Figure 3 shows a typical distribution of $\Delta_{\text {STD }}$ at the station Potsdam. The 2D-histogram presents the frequency of the relative deviation as a function of the elevation $\varepsilon$. The deviation of all STD data is most of the time below $1 \%$ and in the majority of cases below $0.25 \%$ if elevations $\varepsilon>20^{\circ}$ are considered. The mean deviation of all STDs observed at the station Potsdam is $\left\langle\Delta_{\text {obs }}\right\rangle=-8.7 \mathrm{~mm}$ with a RMS of $24.3 \mathrm{~mm}$. Regarding only slants with an elevation above $20^{\circ}$ leads to $\left\langle\Delta_{\text {obs }}\right\rangle=-0.6 \mathrm{~mm}$ and $\mathrm{RMS}=7.4 \mathrm{~mm}$. The variance increases with a decreasing elevation of the slant path but more noticeable is the increasing deviation from the model predictions below $\sim 20^{\circ}$. $\Delta_{\text {STD }}$ increases mainly due to the ray bending which was neglected. The delays simulated with the model are therefore systematically overestimated. However, it is well known that low ele-

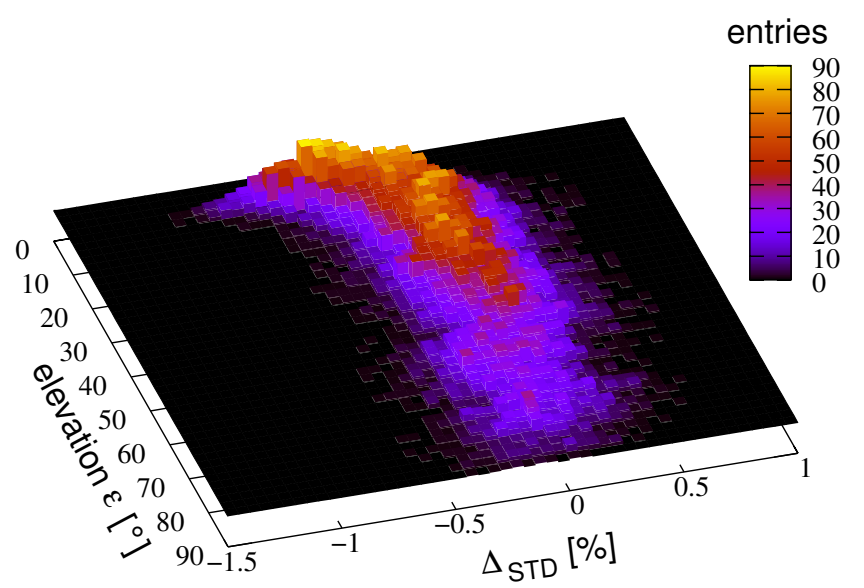

Figure 3: The relative deviation of the slant total delays at the station Potsdam. The deviation $\Delta_{\mathrm{STD}}$ from the model is strongly correlated with the elevation $\varepsilon$. The difference is very small in zenith direction $\left(\varepsilon=90^{\circ}\right)$ but increases significantly below $20^{\circ}$ mainly due to ray bending. The 2D histogram shows the number of entries (colour code) in each interval $\varepsilon=2^{\circ}, \Delta_{\mathrm{STD}}=0.05 \%$.

vation slant delays are difficult to analyse (BEVIS et al., 1994) and efforts have to be made to refine the processing strategies. This is not only important because of the large number of observations below $\varepsilon \sim 30^{\circ}$ but also because of their importance for the spatial reconstruction of the atmosphere. The GPS slant delay is an integral value which cannot provide any information about the distribution along the slant path. As a consequence only the horizontal projection of the slant delay provides information about the vertical structure of the atmosphere (BENDER and RAABE, 2007).

\section{Conclusion and outlook}

The validation of the GFZ GPS slant delay data with a water vapour radiometer and a weather model provided evidence for a high correlation between the compared data. The slant total delays as well as the slant wet delays agree very well for all three methods. The mean deviation between the zenith delays are as small as 1.2 $\mathrm{mm}$ in comparison with the WVR and $3.3 \mathrm{~mm}$ for the weather model. Both studies yield increasing deviations at low elevations.

The quality of the tropospheric slant delays is affected negatively by various error sources, e. g. PCV and multipath effects. Especially observations at low elevation angles are affected by these errors and efforts were made to reduce these effects by the application of stacking techniques. This technique could reduce the RMS but had little impact on the bias. Further studies are therefore required to improve the quality of the GPS slant delays at low elevation angles.

Comparing the results from two experiments results principally in a convolution of the errors from both 
methods and it is not possible to identify the quality of their results independently. As there is no high quality reference available several independent validation studies using different types of observations are necessary to estimate the GPS errors realistically. Furthermore, different weather situations should be investigated systematically in future studies. Several uncertainties of the GPS analysis depend sensitively on the amount and distribution of water vapour in the atmosphere, atmospheric gradients and other meteorological conditions which change considerably with the weather situation. The ray bending should be considered in a following study to make also the low elevation slant delays computed from the weather model suitable for intercomparison studies.

There are several possibilities to utilise the information provided by the slant delays: Tomographic techniques can be used to reconstruct a spatially resolved field of the refractivity or the water vapour directly from the GPS observations. These fields could be used for nowcasting or assimilated to weather models. Another possibility is to assimilate the slant delays directly to the model using advanced assimilation strategies such as 4D-VAR (ZUS et al., 2008). This way, the enhanced humidity information provided by GPS can contribute to more reliable weather forecasts and especially precipitation forecasts.

\section{Acknowledgements}

The authors would like to thank W. WERGEN, Ch. SCHRAFF and Ch. KOZIAR from the German Weather Service (DWD) for providing COSMO-EU analyses and weather data and Maria TOMASSINi for detailed information about the COSMO-EU model. We thank W. SCHWARZ of the Bundesamt für Kartographie und Geodäsie (BKG) for providing the WVR data of Wettzell.

\section{References}

Bender, M., A. RAABe, 2007: Preconditions to groundbased GPS water vapour tomography. - Ann. Geophysicae 25, 1727-1734.

Bevis, M., S. Businger, T.A. Herring, C. Rocken, R.A. ANTHES, R.H. WARE, 1992: GPS meteorology: Remote sensing of atmospheric water vapor using the global positioning system. - J. Geophys. Res. 97, 15787-15801.

BeVis, M., S. Businger, S. Chiswell, T.A. Herring, R.A. Anthes, C. Rocken, R.H. WARE, 1994: GPS meteorology: Mapping zenith wet delays onto precipitable water. - J. Appl. Meteor. 33, 379-386.

Boehm, J., A. Niell, P. TREgONING, H. SchuH, 2006: Global Mapping Function (GMF): A new empirical mapping function based on numerical weather model data. Geophys. Res. Lett. 33, L07304.
Crewell, S., M. Mech, T. Reinhardt, C. Selbach, H.-D. BetZ, E. BrocARD, G. Dick, E. O'CONNOR, J. Fischer, T. HANisch, T. HAuf, A. HÜNERBEIN, L. Delobbe, A. Mathes, G. Peters, H. Wernli, V. WulfMEYER, 2008: : The General Observation Period 2007 within the priority programm on quantitative precipitation forecasting: Concept and first results. - Meteorol. Z. 17, 849-866.

Dick, G., G. GendT, C. Reigber, 2001: First experience with near real-time water vapor estimation in a German GPS network. - J. Atmos. Sol. Terr. Phys. 63, 1295-1304.

GENDT, G., G. DICK, W. SOHNE, 1999: GFZ analysis center of IGS - annual report 1998. - In: K. GowEY, R. NeIlan, A. Moore (Eds.), 1998: Technical Reports, 79-87, Pasadena.

Gendt, G., C. Reigber, G. Dick, 2001: Near real-time water vapor estimation in a German GPS network - first results from the ground program of the HGF GASP project. - Phys. Chem. Earth (A) 26, 413-416.

GENDT, G., G. DiCK, C. REIGBER, M. Tomassini, Y. LiU, M. RAMATSCHI, 2004: Near real time GPS water vapor monitoring for numerical weather prediction in Germany. - J. Meteor. Soc. Japan 82, 361-370.

NiELL, A. E., 1996: Global mapping functions for the atmosphere delay at radio wavelengths. - J. Geophys. Res. 101, 3227-3246.

Picone, J.M., A.E. Hedin, D.P. Drob, A.C. Aikin, 2002: NRLMSISE-00 empirical model of the atmosphere: Statistical comparisons and scientific issues. - J. Geophys. Res.Space Phys. 107, 1468.

POTTIAUX, E., R. WARNANT, 2002: First comparisons of precipitable water vapor estimation using GPS and water vapor radiometers at the Royal Observatory of Belgium. GPS Solutions 6, 11-17.

SCHRAFF, C., R. HESS, 2003: A description of the nonhydrostatic regional model LM, part III: Data assimilation. LM Documentation 3, DWD, Offenbach, Germany.

SCHUlZ, J.-P., U. SCHÄTTLER, 2005: Kurze Beschreibung des Lokal-Modells LME und seiner Datenbanken auf dem Datenserver des DWD. - Technical report, Deutscher Wetterdienst, Geschäftsbereich Forschung und Entwicklung, Postfach 100465, 63004 Offenbach (in German).

ShOJI, Y., H. NAKAMURA, T. IWABUChI, K. AONASHI, H. SeKo, K. Mishima, A. ItAGAKI, R. ICHIKAWA, R. OHTANI, 2004: Tsukuba GPS dense net campaign observation: Improvement in GPS analysis of slant path delay by stacking one-way postfit phase residuals. - J. Meteor. Soc. Japan 82, 301-314.

SMITH, E. K., S. WEINTRAub, 1953: The constants in the equation for atmospheric refractive index at radio frequencies. - Proceedings of the I.R.E. 41, 1035-1037.

SOKOLOVSKIY, S., C. RockEN, A. LOWRY, 2001: Use of GPS for estimation of bending angles of radio waves at low elevations. - Radio Sci. 36, 473-482.

SolHeIM, F., J. GODWIN, R. WARE, 1998: Passive groundbased remote sensing of atmospheric temperature, water vapor, and cloud liquid water profiles by a frequency synthesized microwave radiometer. - Meteorol. Z. 7, 370-376.

Zumberge, J. F., M. B. Heflin, D. C. JefFerson, M. M. WATKINS, F. H. WEBB, 1997: Precise point positioning for the efficient and robust analysis of GPS data from large networks. - J. Geophys. Res. 102, 5005-5018.

ZuS, F., M. GRZESCHIK, H.-S. BAUER, V. WULFMEYER, G. DICK, M. BENDER, 2008: Development and optimization of the IPM MM5 GPS slant path 4DVAR system. Meteorol. Z. 17, 867-885. 